\title{
A acuidade da Escola Inclusiva e Especial para a promoção do desenvolvimento
}

\section{social e sustentável}

The acuity of the Inclusive and Special School for the promotion of social and sustainable development

La agudeza de la Escuela Inclusiva y Especial para la promoción del desarrollo social y sostenible

\author{
Rose Kelly Silva Carvalho \\ ORCID: https://orcid.org/0000-0001-8098-7236 \\ Universidade Regional do Noroeste do Estado do Rio Grande do Sul, Brasil \\ E-mail: rkellycarvalho@hotmail.com \\ Leonardo Coelho Ribeiro \\ ORCID: https://orcid.org/0000-0003-1896-0651 \\ Universidade Regional do Noroeste do Estado do Rio Grande do Sul, Brasil \\ E-mail: leonardo.ribeiro@sou.unijui.edu.br \\ Danieli de Oliveira Biolchi \\ ORCID: https://orcid.org/0000-0002-3167-0352 \\ Universidade Regional do Noroeste do Estado do Rio Grande do Sul, Brasil \\ E-mail: danieli.biolchi@unijui.edu.br \\ Airton Adelar Mueller \\ ORCID: https://orcid.org/0000-0001-6270-5856 \\ Universidade Regional do Noroeste do Estado do Rio Grande do Sul, Brasil \\ E-mail: airton.mueller@unijui.edu.br \\ Pedro Luís Büttenbender \\ ORCID: https://orcid.org/0000-0002-7011-8552 \\ Universidade Regional do Noroeste do Estado do Rio Grande do Sul, Brasil \\ E-mail: pedrolb@unijui.edu.br
}

\begin{abstract}
Resumo
A inclusão escolar não se limita apenas a inserir o aluno com necessidades especiais na classe comum. Portanto, para que a inclusão realmente seja eficaz é preciso um currículo adequado às suas necessidades e profissionais devidamente capacitados para atendê-lo. O presente artigo discorrerá sobre a importância da Escola Inclusiva para o desenvolvimento humano e para a promoção do desenvolvimento sustentável, abordando a respeito do currículo, da prática e do cotidiano escolar na Educação Básica Inclusiva. Na sequência abordará a Educação Especial e Inclusiva como sendo essencial para o desenvolvimento humano. Do mesmo modo, relacionará a acuidade da Educação Especial e Inclusiva para o desenvolvimento sustentável. Quanto a metodologia, a pesquisa validar-se-á da prática de análise aplicada e descritiva em relação aos seus objetivos; o método qualitativo quanto à sua natureza; e os métodos bibliográficos e documental quanto aos procedimentos de utilização e coleta de dados. Logo, o objetivo central será discutir a respeito da educação inclusiva com ênfase no currículo, prática docente e o cotidiano escolar, bem como, descrever o desencadeamento histórico e o atraso na inserção do deficiente na sociedade e nas Escolas regulares. Consequentemente, verificar que as legislações existentes que promovem a proteção desses direitos sociais, são insuficientes, visto que, a falta de políticas públicas prejudica o desenvolvimento da área em questão. Além disso, buscar-se-á averiguar a acuidade que a Escola Especial e Inclusiva apresenta para a promoção do desenvolvimento humano, social e sustentável.
\end{abstract}

Palavras-chave: Inclusão; Evolução; Educação; Sociedade; Sustentabilidade.

\section{Abstract}

School inclusion is not just limited to placing the student with special needs in the regular class. Therefore, for inclusion to be really effective, it is necessary to have a curriculum suited to your needs and professionals who are properly trained to serve you. This article will discuss the importance of the Inclusive School for human development and for the promotion of sustainable development, addressing the curriculum, practice and daily school life in Inclusive Basic Education. Next, it will address Special and Inclusive Education as being essential for human development. Likewise, it will relate the accuracy of Special and Inclusive Education for sustainable development. As for the methodology, the research will validate the practice of applied and descriptive analysis in relation to its objectives; the qualitative method as to its nature; and bibliographic and documentary methods regarding the procedures for using and collecting data. Therefore, the main objective will be to discuss about inclusive education 
with emphasis on the curriculum, teaching practice and daily school life, as well as describing the historical triggering and delay in the inclusion of the disabled in society and in regular schools. Consequently, verifying that the existing legislation that promotes the protection of these social rights is insufficient, since the lack of public policies hinders the development of the area in question. In addition, it will seek to verify the accuracy that the Special and Inclusive School presents for the promotion of human, social and sustainable development.

Keywords: Inclusion; Evolution; Education; Society; Sustainability.

\section{Resumen}

La inclusión escolar no se limita a colocar al estudiante con necesidades especiales en la clase regular. Por eso, para que la inclusión sea realmente efectiva, es necesario contar con un currículo adecuado a tus necesidades y con profesionales debidamente capacitados para atenderlo. Este artículo discutirá la importancia de la Escuela Inclusiva para el desarrollo humano y para la promoción del desarrollo sostenible, abordando el currículo, la práctica y la vida escolar diaria en Educación Básica Inclusiva. A continuación, abordará la Educación Especial e Inclusiva como esencial para el desarrollo humano. Asimismo, relacionará la veracidad de la Educación Especial e Inclusiva para el desarrollo sostenible. En cuanto a la metodología, la investigación validará la práctica del análisis aplicado y descriptivo en relación a sus objetivos; el método cualitativo en cuanto a su naturaleza; y métodos bibliográficos y documentales sobre los procedimientos de uso y recolección de datos. Por tanto, el principal objetivo será debatir sobre la educación inclusiva con énfasis en el currículo, la práctica docente y la vida escolar diaria, así como describir el desencadenante histórico y el retraso en la inclusión de las personas con discapacidad en la sociedad y en las escuelas regulares. En consecuencia, constatar que la legislación existente que promueve la protección de estos derechos sociales es insuficiente, ya que la falta de políticas públicas dificulta el desarrollo de la zona en cuestión. Además, buscará verificar la veracidad que presenta la Escuela Especial e Inclusiva para la promoción del desarrollo humano, social y sostenible.

Palabras clave: Inclusión; Evolución; Educación; Sociedad; Sustentabilidade.

\section{Introdução}

Historicamente as pessoas com alguma deficiência eram deixadas à margem da sociedade, em algumas culturas essas pessoas eram até condenadas à morte. A inserção social dessas pessoas na sociedade foi lenta. No contexto brasileiro até meados do século XIX os cuidados eram meramente assistencialistas (Branco et al., 2019).

Com o passar dos anos e a promulgação de legislações as pessoas com deficiências foram adquirindo seus direitos e espaço na sociedade e nas classes comuns. Quando se fala em inclusão ressalta-se a importância de integrá-los na rede regular de ensino. No entanto esse processo ainda está em construção, mas aos poucos foram instaladas mudanças no âmbito social, legal, educacional e na estrutura dos estabelecimentos. A inclusão dos alunos em escolas da rede regular ganhou maior espaço a partir de 1990. No entanto, ainda existem muitas críticas sobre o processo de inclusão na educação brasileira (Costa, 2018).

Pesquisar sobre a educação inclusiva no contexto do século XXI, conforme esclarece Marques (2020) é necessário para poder defender esse grupo que muitas das vezes possui pouca voz ou espaço social. A inclusão ainda não é absoluta, isso porque é comum o distanciamento entre o que é descrito na legislação do que é feito na prática. Ademais algumas escolas e educadores podem não estar totalmente preparados para receber esses alunos. Sobre o currículo nesse contexto inclusivo costuma ser muito mais teórico do que prático.

Em meio a esse cenário de críticas, avanços e questionamentos surgiu o interesse pelo tema. Então foi definido como objetivo para o presente artigo discutir sobre a educação inclusiva na Educação com ênfase no currículo, prática docente e o cotidiano escolar, bem como sobre a essencialidade da educação especial e inclusiva como contributo no desenvolvimento humano e sustentável, e sobre a importância de políticas públicas que fomentem melhores condições e estrutura para a execução da educação inclusiva no Brasil, melhor capacitação dos professores, e o uso de recursos específicos para o desenvolvimento dessa área da educação.

Diversos estudos foram feitos abordando os temas da educação inclusiva, o uso da metodologia científica como instrumento capaz de promover a educação e com foco na sustentabilidade, o papel da educação no processo de formação humana, e a inclusão social de pessoas com deficiências como forma de desenvolvimento social e da própria sustentabilidade social e educativa. 
Mazzotta e D'Antino (2011) escreveram sobre as questões inseridas na compreensão e concretização da inclusão social das pessoas com deficiência, sob uma análise crítica sobre as políticas e normas nacionais e internacionais chegando a conclusão de que a educação, o lazer e a cultura são mecanismos fundamentais de inclusão ou exclusão social.

Kassar (2011), confeccionou um artigo sobre os percursos da constituição de uma política brasileira de educação especial inclusiva apresentando elementos que consolidam a defesa do papel fundamental que as políticas públicas e o governo exercem na área da educação especial e inclusiva.

Em 2018, Gomes e Ferreira produziram um artigo em que descreveram as políticas públicas e suas relações com o desenvolvimento sustentável, abordando inclusive se os Objetivos do Desenvolvimento Sustentável (ODS) elaborados em 2015 pela Organização das Nações Unidas, são capazes de influenciar positivamente na implantação das políticas públicas, e sendo ambos essenciais para o campo da educação e da sustentabilidade.

Em 2020, Mourão e Netto discorreram sobre o modelo inclusivo de desenvolvimento de objetos de aprendizagem acessíveis para auxiliar a educação inclusiva, sendo realizados estudos de caso que comprovaram que a igualdade de oportunidades e a valorização dos estudantes são essenciais para a eficiência da educação inclusiva.

Diante desse contexto de estudo, a presente pesquisa terá como objetivo analisar a importância que as políticas públicas de educação especial e inclusiva tem no tocante à promoção do desenvolvimento humano e sustentável, bem como se as políticas de inclusão na educação tem tido bons resultados, e assim fará abordando os temas citados através de uma abordagem descritiva e bibliográfica, e de análise qualitativa (visto que busca estabelecer uma relação mais intimista e sistêmica), e como os sujeitos da pesquisa os estudantes especiais, dentro do contexto da educação como condição essencial para a promoção do desenvolvimento humano, social e sustentável.

A pesquisa qualitativa não necessita do "uso de métodos e técnicas estatísticas". Nesse tipo de estudo o objetivo é produzir informações aperfeiçoadas e ilustrativas "seja ela pequena ou grande, o que importa é que ela seja capaz de produzir novas informações" (Kauark et al., 2010, p. 26). Esse tipo de pesquisa tem a preocupação com as características de uma determinada realidade que não podem ser medidos. Sendo inclusive a abordagem bastante indicada para pesquisa envolvendo a área da educação (Gerhardt, Silveira, 2009).

Dessa forma, busca-se produzir mais conhecimentos acadêmicos a respeito a inclusão na educação básica. Enfatizando a necessidade de adequação dos currículos de da prática docente almejando uma educação de qualidade para os portadores de necessidades especiais.

A pesquisa bibliográfica, assim descreve Gil (2008, p.28): "pesquisas deste tipo têm como objetivo primordial a descrição das características de determinada população ou fenômeno ou o estabelecimento de relações entre variáveis".

Nas perspectivas de Garcia (2013, p. 293) verifica-se que esse tipo de pesquisa busca "discutir sobre ideologias ou ainda as que buscam conhecer e analisar as contribuições culturais ou científicas do passado sobre um determinado assunto, tema ou problema". Destaca-se que uma pesquisa bibliográfica é diferente de uma revisão bibliográfica onde são apenas feitos relatos de fenômenos sem um posicionamento crítico.

As pesquisas bibliográficas produzem novas informações a partir de materiais já publicados como livros e artigos científicos. Esse estudo não é apenas a repetição de informações, mas sim apresentação de um tema sob várias respectivas, com apontamentos e olhares de diversos estudiosos (Gerhardt, Silveira, 2009).

Embora já existam diversos estudos que falam sobre a questão da inclusão educativa, sobre as políticas públicas na área da educação, e os reflexos e relações existentes entre esses temas e o desenvolvimento social sustentável, essa pesquisa se justifica pois trata de forma correlata essas questões acima, para analisar a importância que a educação especial e inclusiva tem na sociedade contemporânea, trazendo uma ampla reflexão da relevância de igualdade de promover a educação para todos e 
procurará responder a seguinte discussão: se a educação especial e inclusiva tem sido promovida com políticas públicas eficientes e capazes de contribuir com o desenvolvimento humano, social e sustentável no Brasil presente.

\section{Metodologia}

Sobre a abordagem, a presente pesquisa caracteriza-se como qualitativo visto que busca estabelecer uma relação mais intimista e sistêmica. Esse tipo de pesquisa não necessita do "uso de métodos e técnicas estatísticas". Nesse tipo de estudo o objetivo é produzir informações aperfeiçoadas e ilustrativas "seja ela pequena ou grande, o que importa é que ela seja capaz de produzir novas informações” (Kauark et al., 2010, p. 26). Esse tipo de pesquisa tem a preocupação com as características de uma determinada realidade que não podem ser medidos. Sendo inclusive a abordagem bastante indicada para pesquisa envolvendo a área da educação (Gerhardt, Silveira, 2009). No que se refere aos procedimentos técnicos adotou-se a pesquisa bibliográfica com o intuito de levantar informações sobre a educação inclusiva no contexto da Educação Básica, abordando dados históricos e atuais. Conforme acrescenta Gil (2008, p.28) "pesquisas deste tipo têm como objetivo primordial a descrição das características de determinada população ou fenômeno ou o estabelecimento de relações entre variáveis". Nas perspectivas de Garcia (2013, p. 293) verifica-se que esse tipo de pesquisa busca "discutir sobre ideologias ou ainda as que buscam conhecer e analisar as contribuições culturais ou científicas do passado sobre um determinado assunto, tema ou problema". Destaca-se que uma pesquisa bibliográfica é diferente de uma revisão bibliográfica onde são apenas feitos relatos de fenômenos sem um posicionamento crítico. As pesquisas bibliográficas produzem novas informações a partir de materiais já publicados como livros e artigos científicos. Esse estudo não é apenas a repetição de informações, mas sim apresentação de um tema sob várias respectivas, com apontamentos e olhares de diversos estudiosos (Gerhardt, Silveira, 2009).

\section{Resultados e Discussão}

\section{1 Educação Especial no Contexto Histórico}

Foi a partir da Declaração Universal dos Direitos Humanos de 1948, adotada pela Organização das Nações Unidas (ONU), que se iniciou a preocupação com a educação inclusiva. Essa Declaração foi o primeiro marco da educação inclusiva, considerada a mais importante. Essa Declaração embora não tivesse status de lei, estabeleceu em seu artigo primeiro a igualdade entre as pessoas e que todas possuem os mesmos direitos legais (Cantini, Ribeiro, 2019).

No Brasil, as discussões sobre essa temática ganharam evidência, em 1961, com a publicação da Lei de Diretrizes e Bases da Educação Nacional (LDB) que definia os deficientes como "excepcionais". Esse dispositivo legal passou a reconhecer os direitos dos deficientes à educação, que teriam direito a integrar os sistemas de ensino. No entanto, essa legislação não se compromissava com a educação pública, apoiando apenas instituições privadas (Corrêa, 2010).

Em 1971 em detrimento de mudanças no âmbito político brasileiro surge uma nova Lei de Diretrizes e Bases da Educação Nacional que estipulava que os alunos que possuíssem deficiências físicas ou mentais que apresentassem atraso considerável com relação à idade regular de matrícula e os superdotados deveria ter um tratamento especial. Destaca-se que essa legislação não proporcionou uma educação inclusiva eficaz, e sim reforçava a exclusão e até mesmo "segregação do deficiente" pelo fato de estimular a matrícula desses alunos em classes e escolas especiais, predominando nesse período, o atendimento de caráter assistencialista (Branco et al., 2019).

Com a publicação da Constituição Federal de 1988 a educação passou a ser reconhecida como direitos de todos. Foi garantido igualdade de condições de acesso e permanência na escola. $\mathrm{O}$ atendimento educacional para as pessoas com deficiência passou a ser preferencialmente na rede regular de ensino. Essa legislação constituiu-se em um marco educacional inclusivo, pois a partir de então foi assegurado oportunidades educacionais iguais para todos os alunos (Prestes, 2015). 
Com a Lei 7853 de 1989 passou a ser crime as instituições escolares recusarem alunos por apresentarem alguma deficiência. Em 1990 ocorreu a Conferência Mundial de Educação para Todos em Jomtien que resultou em dois documentos: o Marco de Ação para Satisfazer as Necessidades Básicas de Aprendizagem e a Declaração Mundial de Educação para Todos. Esse último aborda a necessidade de atenção com a aprendizagem das pessoas com deficiências (Jacomeli et al., 2018).

A Declaração de Salamanca (1994) é uma resolução da Organização das Nações Unidas (ONU) resultado da Conferência Mundial sobre Necessidades Especiais. Essa conferência buscou promover a educação para todos com enfoque em uma educação integradora e inclusiva. Na declaração foi estipulado que toda criança tem direito a educação e condições que favoreçam seu aprendizado precisam ser promovidas (Corrêa, 2010).

A Lei de Diretrizes e Bases da Educação Nacional publicada em 1996, lei que regulamenta a educação formal até os dias atuais, estipulou quando necessários os deficientes terão direito a serviços de apoio especializado, na escola regular, para atender suas peculiaridades. Ademais, a legislação aponta a necessidade de currículos, professores e métodos especializados para atender esses educandos.

A partir da publicação da Lei $\mathrm{N}^{\circ} 10.436$, de 24 de abril de 2002 ocorreu um avanço inclusivo direcionado para as comunidades surdas. Já que com essa legislação os surdos passaram a ter o reconhecimento de sua formação de identidade própria. Com essa legislação passou a ser garantido que Língua Brasileira de Sinais - Libras não poderia substituir a modalidade escrita da língua portuguesa. Sendo assim as escolas precisam disponibilizar na classe comum, junto ao professor regente, um profissional especializado para atender os alunos surdos.

O Decreto n. 6.571 de 2008 estipulou o atendimento especializado (AEE) na educação Básica. Esse atendimento deve ter função de complementar ou suplementar a aprendizagem do educando com necessidades especiais. Com esse decreto a União passou a ter que oferecer apoio técnico e financeiro aos sistemas educacionais públicos na oferta de educação inclusiva. Em 2009 foi publicada a resolução número 4 com Diretrizes Operacionais para o Atendimento Educacional Especializado na Educação Básica. Essa resolução serve para orientar os sistemas de ensino no cumprimento do decreto n. 6.571 de 2008 (Costa, 2018).

Em 2014 foi publicado o Plano Nacional da Educação (PNE) com 20 metas para a educação. Na meta de número 4 foi estipulado a universalização o acesso e atendimento educacional especializado preferencialmente na rede regular de ensino para educandos com deficiência, transtornos globais do desenvolvimento e altas habilidades ou superdotação na faixa etária de 4 até 17 anos, sendo garantido um sistema educacional inclusivo, com salas de recursos e serviços especializados para esses educandos.

Outro avanço em termos legais foi a publicação da Lei $\mathrm{N}^{\circ}$ 13.146, de 6 de julho de 2015 com a finalidade de garantir e permitir condições de igualdade e exercício dos direitos fundamentais para pessoas com deficiências, almejando a sua inclusão social. Essa lei garante inclusão tanto no espaço escolar como nos demais locais da sociedade. Inclusive garante formas de comunicação diversas de acordo com as diferentes deficiências. Isso porque a lei estipula uma educação bilíngue onde a Libras deve ser a primeira língua e a modalidade de escrita portuguesa deve ser a segunda. Além disso, também há incentivo na oferta de libras, sistema de braile e uso de recursos de tecnologia assistida como forma promover a autonomia dos educandos.

A inclusão vai além da publicação de legislações. É preciso que no convívio social o indivíduo tido como deficiente tenha suas limitações respeitadas. As práticas inclusivas devem estar sempre presente na sala de aula. As metodologias alternativas como jogos, materiais didáticos enriquecem o aprendizado dos educandos, inclusive dos que não apresentam deficiências (Costa, 2018).

É notável o aumento do percentual de alunos com deficiência, transtornos globais do desenvolvimento ou altas habilidades, matriculados em classes comuns em todas as etapas da Educação Básica. Exceto no Ensino de Jovens e Adultos 
(EJA), as demais etapas apresentam mais de $80 \%$ de alunos incluídos em classe comum em 2019. A maior taxa de inclusão pode ser verificada no Ensino Médio e na educação profissional (Censo da Educação Básica, 2020).

E a Agenda Global 2030, coordenada pelas Nações Unidas, caminha no sentido de promover a inclusão quando propõe o objetivo 4 que busca assegurar a educação inclusiva e equitativa para todos ao longo de suas vidas. É uma necessidade urgente aprofundar e explanar as discussões teóricas e práticas para o empoderamento e protagonismos das pessoas com deficiência, já que Constituição Federal prevê que a educação é direito de todos e estipula igualdade de condições e permanência para os alunos na escola.

\subsection{Educação Inclusiva e o Currículo Escolar}

A educação inclusiva é uma modalidade de ensino que está presente em todas as etapas da educação básica e até mesmo no ensino superior. A inclusão escolar tem sido um assunto bastante enfatizado já que o número de alunos com deficiências matriculados em classes comuns vem aumentando. Para que realmente a educação escolar seja inclusiva é preciso o engajamento da família, dos professores e demais pessoas envolvidas na reação aluno e escola. Esse acolhimento escolar deve envolver desde professores capacitados até mesmo currículos inclusivos (Zanato e Gimenez, 2017).

Uma análise geral sobre currículo embasado nos estudos de Sacristán, constata-se que o currículo não é um conceito e sim uma construção de cultura. A partir do currículo é possível organizar diversas práticas educativas. O currículo está relacionado à experiência humana. $\mathrm{O}$ autor completa que para a compreensão do currículo em um sistema educativo é preciso:

(...) prestar atenção às práticas políticas e administrativas que se expressam em seu desenvolvimento, às condições estruturais, organizativas, materiais, dotação de professorado, à bagagem de ideias e significado que lhe dão forma e que o modelam em sucessivos passos de transformação (Sacristán, 2000, p. 1).

A relação entre currículo e educação inclusiva é tido como um assunto polêmico e que resulta em dúvidas. Ainda é comum a ideia de que o currículo deve ser diferenciado e "com uma sequência de atividades de vida diária e social ou a redução de conteúdo disciplinares que marginalizam as diferenças”. Muitas das vezes o currículo é tido como um guia para as atividades pedagógicas. Mas não se pode tê-lo como receita pronta. Já que cada aluno tem suas diferenças, dificuldades de aprendizagens distintas (Mercado e Funes, 2017).

Sob a perspectiva de Zanato e Gimenez (2017) o currículo inclusivo é aquele em que as peculiaridades do aluno são reconhecidas e respeitadas. E por isso que os contextos educacionais precisam ser flexíveis e o papel do currículo nesse espaço é nortear as necessidades educacionais de cada aluno. Coelho et al. (2019) complementam que um currículo inclusivo deve ser aquele que:

(...) romper com práticas excludentes e concepções pedagógicas conservadoras. Para efetivar a inclusão escolar dos alunos com deficiência é preciso, portanto, transformar a escola, questionar concepções e valores, visto que não se trata de adequar as práticas educacionais, mas transformá-las em função do desenvolvimento e aprendizagem dos estudantes (Coelho et al., 2019, p. 22).

Zanato e Gimenez (2017) seguem relatando que a inclusão efetiva dos alunos na rede regular se dá por meios de adaptações curriculares levando-se em consideração as limitações singulares de cada um. Para Mesquita (2010) as adaptações curriculares são capazes de facilitar o trabalho do educador junto aos alunos com deficiências. Porém nesse processo de adaptação deve ser tomado cuidado para não construir um currículo excludente no sentido de separação entre alunos tidos como deficientes e os alunos não deficientes. Santos e Lima (2020, p.64) mencionam que os: 
(...) os profissionais que atuam no ensino comum apresentam, ainda, desconhecimento sobre as peculiaridades das deficiências, falta de reconhecimento das potencialidades destes estudantes e falta de flexibilidade quanto ao currículo para atender às necessidades de aprendizagem destes (Santos e Lima, 2020, p.64).

Sobre essas adaptações curriculares Paula e Silva (2016) explicam que trata se alternativas que a escola deve criar diante das dificuldades dos educandos para que o currículo possa atender as necessidades especiais particulares dos estudantes. As autoras esclarecem que não se trata da construção de um novo currículo e sim a sua flexibilização de forma a favorecer a aprendizagem do educando. Para Santos e Lima:

Compreendida a necessidade da adaptação curricular aos estudantes deficientes, o professor precisa refletir sobre o currículo proposto, questionar os conteúdos existentes e objetivos previamente definidos, tendo como parâmetro a realidade. Isso requer um profissional embasado teoricamente para justificar as suas decisões e devidamente implicado com a realidade e com o processo de aprendizagem (Santos e Lima, 2020, p.67)

Nesse contexto curricular as atividades propostas não devem ser fáceis e sem contexto, apenas para entreter os educandos. É possível que o educando com necessidades especiais possa ter um mediador. Que é compreendido como um profissional que dever "ser entendido como parte constituinte do currículo escolar, uma vez que possui participação no movimento educacional cotidiano da instituição pedagógica a qual pertence". Os autores explicam que esses profissionais são considerados um segundo docente possibilitando um currículo mais acolhedor ao aluno. Além disso seu papel vai além de promover a inclusão, proporciona uma adequação curricular ao educando de acordo com suas particularidades (Moreira e Cruz, 2018, p.141).

Quando se fala em auxílio a aprendizagem de alunos deficientes auditivos se destaca o papel do intérprete de libras que irá assumir diferentes papéis na sala de aula, "ensinar ao surdo a língua portuguesa como segunda língua, ensinar a língua de sinais aos surdos e ouvintes a fim de facilitar a interação na comunicação". Além disso, é papel desse profissional fazer adequações curriculares, planejando as aulas em conjunto com o professor responsável pela classe. Ressalta-se que esse profissional que irá atuar na educação básica precisa ter no mínimo ensino médio completo e certificado de proficiência na Libras (Vargas e Rodrigues, 2018).

\subsection{A Relação entre a Prática Docente e o Cotidiano Escolar}

A Lei Brasileira de Inclusão da Pessoa com Deficiência (2015) estipula que é dever do Estado, família, escola e sociedade em geral assegurar a educação às pessoas com deficiências, deixando protegidas de qualquer forma de violência, negligência e discriminação. Nesse contexto cabe aos sistemas educacionais o dever de proporcionar um ambiente seguro e inclusivo aos educandos com deficiências.

É responsabilidade de profissionais específicos capacitados apresentar o diagnóstico sobre doenças ou transtornos. No entanto, é comum os professores verificarem alguns sintomas e comunicarem aos pais que posteriormente levam a criança a um profissional. A instituição escolar é um local privilegiado para auxiliar pessoas com dificuldades e também é o espaço onde se aprende e ensina sobre a inclusão e respeito às diferenças (Costa, 2018).

Sobre a prática do professor em sala com alunos com deficiências, Silva e Arruda (2014) explicam que muitos professores se sentem inseguros, pois na sua formação inicial aprenderam a atender esses alunos apenas de forma teórica. Quando na turma existem alunos com necessidades especiais é preciso que o professor se organize e planeje um novo espaço de aprendizagem de forma que favoreça a todos educandos. 
Por isso Amaral (2017) enfatiza a necessidade de formação continuada para esses profissionais atuantes, pois assim eles podem aperfeiçoar sua prática e promover uma educação mais igualitária. Os educadores precisam estar preparados para atender esses alunos e isso exige que ele reveja sua prática e esteja disponível a adquirir novos conhecimentos.

Para Santos e Lima (2020) a inclusão escolar envolve educação de qualidade, sendo assim os educadores precisam estar capacitados para atender esse público e suas particularidades. Pois a falta de professores qualificados para essa situação resulta em uma "pseudo-inclusão", isto é, apenas a alocação de deficientes na classe comum, mas sem realmente incluí-los como sujeito do processo ensino aprendizagem.

A escola deve ser igualitária, proporcionar o desenvolvimento de todos os educandos sem distinção. Para Rubira et al. (2011) quando se fala em inclusão está também falando em cidadania. Já que a inclusão busca promover os direitos sociais, a participação da pessoa deficiente em todos os contextos sociais e nesse processo o professor é umas das peças principais.

\subsection{A Educação Especial e Inclusiva Essencial ao Desenvolvimento Humano}

Pesquisas e estudos realizados sobre a inclusão escolar demonstram que há uma grande importância na política inclusiva instituída pela Constituição Federal de 1988, colocando a educação como um direito social e de todos e propiciando a convivência escolar em meio a diversidade e as diferenças culturais e individuais existentes (Carvalho, 2008).

A proposta inicial que direcionou a educação inclusiva como forma de acolhimento humano foi, segundo Batista e Enumo (2004) primeiramente instituída no ano de 1972, através de um grupo especializado em Educação Especial na Escandinávia, capitaneado por Wolfensberger, sob o princípio denominado princípio da normalização, que defende que as pessoas com deficiências possuem direito de gozar a vida de forma mais normal possível em sua sociedade, dando-lhes oportunidades, e tendo suas diferenças respeitadas e suas necessidades atendidas.

Diversas normas foram criadas, como a Lei. 7.853/89, após o decreto-lei 3.298/99, visando tornar a sociedade mais acolhedora aos deficientes, como por exemplo, determinando que os estabelecimentos públicos de ensino sejam obrigados a ofertarem a educação especial, e depois que todas as escolas públicas quanto privadas fossem obrigadas a fornecer programas de apoio aos estudantes especiais nas escolas regulares ou mesmo nas escolas especializadas, principalmente quando as escolas comuns não poderiam atender as demandas educacionais e sociais do aluno e promover o bem estar do educando.

Depois foram criadas as Diretrizes Nacionais para a Educação Especial na Educação Básica através da Resolução CNE/CEB n $2 / 2001$, que determinou no artigo $2^{\circ}$ : "Os sistemas de ensino devem matricular todos os alunos, cabendo as escolas organizar-se para o atendimento aos educandos com necessidades especiais, assegurando as condições necessárias para uma educação de qualidade para todos". (MEC/SEESP, 2001). Em 2003 o Ministério da Educação através da Secretaria de Educação Especial implantou o Programa Educação Inclusiva concedendo o direito à diversidade, visando transformar as escolas em sistemas inclusivos de ensino e assim todos terem acesso à educação, como forma de promoção ao perfeito e saudável desenvolvimento humano.

De forma inédita, o Ministério Público Federal em 2004, e com base no Decreto n. ${ }^{\circ}$ 3.956/2001, publicou um documento chamado: O Acesso de Alunos com Deficiência às Escolas e Classes Comuns da Rede Regular, objetivando tornar praxe as diretrizes mundiais de inclusão das pessoas com deficiência e/ou especiais na área da educação de forma que alunos com ou sem deficiência pudessem frequentar as turmas de ensino comum e de ensino regular.

De 2004 a 2007 foi implementado o Plano Brasil de Todos: participação e inclusão. E de 2008 a 2011, o Plano Desenvolvimento com inclusão social e educação de qualidade. Esses períodos foram cruciais tendo a educação sido apresentada, ao menos em tese, como prioridade nacional, e que deveria promover a equidade, proporcionar a inclusão social e a valorização da diversidade. 
Em 2008 foi implementado o Decreto 6.571, e em seu art. 1': "Para a implementação do Decreto 6.571/2008, os sistemas de ensino devem matricular os alunos com deficiência, transtornos globais do desenvolvimento e altas habilidades/superdotação nas classes comuns do ensino regular e no Atendimento Educacional Especializado (AEE), ofertado em salas de recursos multifuncionais ou em centros de Atendimento Educacional Especializado da rede pública ou de instituições comunitárias, confessionais ou filantrópicas sem fins lucrativos. Art. $2^{\circ}$. O AEE tem como função complementar ou suplementar a formação do aluno por meio da disponibilização de serviços, recursos de acessibilidade e estratégias que eliminem as barreiras para sua plena participação na sociedade e desenvolvimento de sua aprendizagem. Parágrafo Único. Para fins dessas Diretrizes, consideram-se recursos de acessibilidade na Educação aqueles que asseguram condições de acesso ao currículo dos alunos com deficiência ou mobilidade reduzida, promovendo a utilização dos materiais didáticos e pedagógicos, dos espaços, dos mobiliários e equipamentos, dos sistemas de comunicação e informação, dos transportes e dos demais serviços. (CNB/CNE, 2009).

A última regulamentação implementada no Brasil sobre o sistema educacional foi o Plano Nacional de Educação (PNE 2011-2020), que contém, entre outras metas e projetos inclusivos, uma nova função da Educação Especial colocando-a como uma modalidade de ensino que vai além dos parâmetros tradicionais de escolarização (Educação infantil ao ensino superior, pois determina que haja o atendimento educacional especializado com serviços e recursos próprios, bem como tem o dever de dar as diretrizes aos alunos e professores quanto à seu uso nas turmas regulares. O Plano Nacional de Educação atua na Educação inclusiva com alunos com deficiência (intelectual, física, auditiva, visual e múltipla), com transtorno global de desenvolvimento, e com altas debilidades funcionais.

Segundo Ferreira e Ferreira (2007) as escolas passaram a alocar a educação especial como responsabilidade às escolas da educação especial, deslocando a função da educação especial para os especialistas.

Já para Batista e Enumo (2004) colocar estudantes especiais em turmas de ensino regular contribui para uma maior interação com os professores e estudantes, diminuindo o preconceito e a discriminação que passam os alunos especiais e deficientes.

A inclusão de pessoas com deficiências, segundo Mantoan (1998), fez com que fosse percebido que é preciso haver muitas modificações na sociedade afim de que seja apta a receber os alunos especiais, devendo esse problema ser tratado como um problema institucional e social.

A prática da inserção dos alunos especiais nos diversos núcleos sociais, inclusive na área da educação é importante e pedagógico, necessária para a interação e aprendizagem de todos os demais alunos, os com e sem deficiências, colaborando para de uma forma justa, a escola seja um ambiente sem discriminações e privilégios, e possa ser ao mesmo tempo um local com maior percepção das dificuldades humanas, e assim ser visto como um local seguro e confortável de aceitação social (Carvalho, 2008; Lima, 2006).

Apesar de no Brasil foi estabelecido que deve haver a inclusão de pessoas com deficiência no sistema de ensino comum, como acontece em muitos outros países, há países que separam e determinam que o sistema de ensino para esses alunos tenha de ser de forma especializada e exclusiva dos demais.

No entanto, constata-se hoje que a educação inclusiva pode oferecer uma série de benefícios acadêmicos e sociais para os alunos portadores de deficiência ou de necessidades especiais, como por exemplo a melhora na linguagem e no raciocínio matemático, melhor interação social e com os colegas sem deficiência, e melhor desempenho escolar. Mesmo assim há certo receio por parte de muitos pais e professores de que as adaptações que os estudantes especiais necessitam para o acesso e acomodação nas salas de aula atrapalhem o aprendizado dos alunos sem deficiência, conforme relata Peltier (1997).

De forma contrária, vários estudos recentes vêm mostrando que a inclusão dos alunos especiais e ou deficientes aos alunos sem problemas dessa ordem, pode oferecer certos benefícios sociais e acadêmicos, como obtido pelos estudos de Ruijs 
e Peetsma (2009) e que concluiu que essa junção no sistema de ensino traz resultados acadêmicos positivos ou neutros nos alunos sem deficiência.

O maior dissenso ocorre ainda quanto a junção de alunos com deficiências emocionais graves, pois parte dos pesquisadores, como Fletcher (2010) e Gootfried (2014) constataram que a deficiência emocional grave pode causar um impacto negativo nas habilidades de leitura e de operações matemáticas nos alunos sem deficiência. Contudo há de se destacar que o percentual desses alunos é quase insignificante.

A formação dos professores e o uso de estratégias pedagógicas específicas pode fazer auxiliar os programas inclusivos a beneficiarem todos os alunos, conforme bem pontua Sharma et al (2008).

Outra grande colaboração para o desenvolvimento humano em ambos os alunos pode se dar na questão do desenvolvimento socioemocional, principalmente aqueles que não tem deficiência. Benefícios tais como redução do medo das diferenças humanas, aumento da cognição ou receptividade social, maior eficácia na comunicação entre os colegas, aumento da autoestima, desenvolvimento dos princípios morais e éticos, diminuição do preconceito, dentre outros (Staub e Peck, 1995).

Segundo um estudo realizado por Herir, Grindal e Eideman (2012) nos Estados Unidos, com mais de 68 mil alunos com deficiência, os alunos com deficiência que passaram maior tempo na escola em contato com os alunos sem deficiência, obtiveram melhor desempenho do que os alunos que estudavam em escolas exclusivas e de forma segregada.

Estudos feitos em outros países como na Noruega e na Holanda também demonstraram a existência de benefícios com melhora no desempenho escolar na educação inclusiva (Myklebust, 2007; Peestma et al, 2001).

Até mesmo estudos feitos com crianças portadoras de Síndrome de Down na Holanda (De Graaf e Van Hov (2015), apontaram para uma melhoria significativa no desenvolvimento das habilidades acadêmicas de leitura, escrita, linguagem e matemática, no ensino inclusivo.

Vygotski (1983) elaborou importantes estudos no campo do desenvolvimento humano nas pessoas com deficiência, discorrendo sobre a deficiência e a educação e defendeu que o desenvolvimento intelectual das pessoas com deficiência pode ocorrer por mecanismos compensatórios, e com isso as pessoas deficientes não estão sujeitas ao fracasso. O trabalho educativo, segundo o autor, deve procurar superar as deficiências a partir do ensino, sendo o deficiente um ser capaz de desenvolver todo o seu potencial, tendo a educação um importante papel no desenvolvimento da linguagem, do pensamento e da consciência.

Mendes (2012) defendeu a Educação Inclusiva como uma forma de aplicação da pedagogia de forma não homogeneizadora, e capaz de desenvolver as competências interpessoais, estimulando as habilidades morais para uma convivência mais harmoniosa e democrática, e de uma forma geral, uma melhor educação para todos.

\subsection{A Educação Especial e Inclusiva: Relação e Importância para o Desenvolvimento Sustentável}

É inegável que houve avanços significativos nos últimos anos na normatização social das pessoas com deficiência. No entanto, conforme enunciou Garcia e Pereira (2018) ainda há muito espaço para a evolução dos deficientes no que diz respeito à tratamentos com médicos e especialistas, melhoria de qualidade na infraestrutura urbana e dos transportes a fim de adequá-la, bem como no ensino, no respeito e no trato de toda a sociedade, com uma cultura de aceitação e acolhimento por parte de todos.

Há uma ideologia de "normalidade" que alimenta preconceitos, omissões e barreiras na relação com os deficientes, conforme cita Ribeiro et al (2017), e que somente com o tempo e de forma lenta haverá a evolução social de aceitação e as mudanças necessárias ao convívio digno e condizente na sociedade contemporânea.

A educação especial no Brasil, conforme aduz Castro (1986) teve início em 1854, com a criação do Instituto Benjamin Constant e do Instituto Nacional de Educação para os Surdos, em 1857, fomentando a pesquisa sobre as demandas sociais a esse respeito, que até então eram ignoradas. 
A importância social da educação inclusiva é tamanha que ao firmarem o acordo denominado Agenda 2030, os países signatários estabeleceram ODS, objetivos do Desenvolvimento Sustentável, e nos ODS 4 e 10, a Unesco instituiu como prioridade o paradigma da inclusão social em todas as classes, meios e esferas sociais, visando assim construir uma sociedade mais igualitária, justa e inclusiva (2015).

Através desse documento, os Estados membros se comprometeram na meta de construir instalações educacionais adaptadas e adequadas a crianças deficientes, e a busca constante pela prevenção da exclusão social e da marginalização. E no ODS 10, se comprometeram com a redução das desigualdades, e promover inclusão social, política e econômica de todos, sem distinção de gênero, sexo, idade, deficiência, raça, religião, etnia, condição econômica e social, ou qualquer outra distinção (UNESCO, 2017).

Os países signatários assim acordaram em defender em âmbito nacional e internacional a promoção da inclusão social, o que demonstra que a educação especial e inclusiva é parte essencial na promoção do desenvolvimento humano e sustentável.

A inclusão social dos deficientes e a educação especial fazem parte desse importante pacto internacional, e apoiada por importantes organizações internacionais como a ONU (Organização das Nações Unidas) e pela própria Unicef, e submetida e aprovada por 161 países, em que cada qual assumiu a importante missão de defender e promover ações afirmativas na educação inclusiva, que muitas vezes enfrenta resistência pelos fatores políticos e culturais de países, que acabam se conformando com a segregação em vem de inclusão social.

Um dos principais mecanismos que um país tem para viabilizar o desenvolvimento da educação especial e inclusiva e assim fazer cumprir o acordo firmado da Agenda 2030 é a criação e implementação de políticas públicas, com o estabelecimento de metas a cumprir, promover campanhas públicas nos estados e municípios que defendam e apoiem a educação inclusiva, construir sistema de coleta de dados a fim de estabelecer um controle, fiscalização e monitoramento sobre as ações instituídas e prevenir os riscos e falhas nesses programas de políticas públicas, e ainda proporcionar aos professores programas de formação específica para aprenderem a lidar com a educação inclusiva.

A implantação das políticas públicas são assim fundamentais para a promoção da inclusão social, lutar pela igualdade de direitos e pelas práticas inclusivas, combatendo preconceitos e concepções erradas, e na promoção de campanhas educativas que demonstrem a importância de que as pessoas com deficiência e ou especiais tenham acesso a um sistema de ensino afetivo e acolhedor, e assim alcançar os objetivos desejáveis. Professores qualificados, bem como também os próprios pais de alunos são peças essenciais na parceria política educativa que precisa haver, e com a determinação de todos, mostrar que a diferença não pode distanciar as pessoas, e sim uni-las em prol de um mesmo objetivo, o da defesa dos direitos individuais e coletivos, tendo a educação como um dos mais importantes direitos sociais consagrados pela Constituição Federal.

\section{Conclusão}

$\mathrm{O}$ acesso à educação passou a ser tratada de forma mais incisiva nas últimas décadas, como forma de reverberação da evolução social e tecnológica observada no mundo contemporâneo.

A partir de então, nota-se que as pessoas portadoras de deficiências passaram a adquirir direitos de forma vagarosa, as legislações aos poucos foram contribuindo e desenvolvendo avanços positivos na inclusão. No contexto educacional uma educação inclusiva demanda não apenas de legislação e normas regulamentadoras, como também uma prática docente capacitada com adequações curriculares.

Salienta-se que apenas legislações não garantem eficácia de aprendizado, ter um aluno matriculado na rede regular de ensino não é garantia de inclusão. Para a aprendizagem de qualidade do educando o currículo escolar deve respeitar as diferenças dos alunos deficientes. Logo, um currículo inclusivo deve ser flexível e norteador, com adaptações curriculares, mas 
sem tratar o aluno deficiente com diferente dos demais da classe. As atividades apresentadas na sala de aula devem proporcionar interações entres os alunos tidos como deficientes e não deficientes.

Averiguou-se que a inserção de mediadores na classe comum para auxiliar os educandos com necessidades especiais é uma forma de proporcionar a adequação curricular e consequentemente favorecer a aprendizagem. Quando se fala em alunos com deficiências auditivas, salienta-se que o profissional que irá acompanhar esse educando precisa ser devidamente capacitado em nível mínimo de especialização.

No que tange a prática docente e cotidiano escolar inclusivo pontua-se que muitos educadores se sentem despreparados em virtude de sua formação inicial. Eles têm o conhecimento teórico, mas carecem de práticas. Logo faz-se necessário que eles busquem formação continuada para poder melhor atender os alunos.

E ainda ficou demonstrado que a educação inclusiva é muito relevante para o desenvolvimento próprio de ambos os alunos, e não somente para os alunos com deficiências e ou especiais, e que gera uma maior humanização destes e dos professores, sendo de grande valor para a educação de uma forma em geral.

Tanto é assim que a Agenda 2030 que se constitui como um grande acordo internacional em prol do desenvolvimento de forma sustentável, instituiu em seus artigos 4 e 10 metas desafiadoras para os países pactuantes a fim da promoção do desenvolvimento e uma maior expansão da educação inclusiva como uma das grandes metas a serem cumpridas, o que corrobora para sustentar a relação e a importância que a educação especial tem para a promoção do desenvolvimento sustentável tanto no Brasil como nos países em todo o mundo.

\section{Referências}

Amaral, M. M. Políticas públicas de Formação Continuada de professores para a Educação Inclusiva no Brasil: o que temos para hoje? Revista Educação, Artes e Inclusão, v. 13, n. 3, p. 120-140, 2017.

Batista, M. W.; Enumo, S.R.F. Inclusão escolar e deficiência mental: Análise da interação social entre companheiros. Estudos de Psicologia, v.9, n.1, 101-111, Natal, 2004.

Branco et al. Políticas educacionais e o direito à educação do deficiente no Brasil. In: Anais da IX jornada Internacional de Políticas Públicas, São Luís (MA), 2019. < http://www.joinpp.ufma.br/jornadas/joinpp2019/images/trabalhos/trabalho_submissaoId_666_6665cbc681c98cfd.pdf>

BRASIL. Lei nº 4.024, de 20 de dezembro de 1961. <http://www.planalto.gov.br/ccivil_03/leis/L4024.htm>.

BRASIL. Lei no 5.692 de 11 de agosto de 1971 < https://www2.camara.leg.br/legin/fed/lei/1970-1979/lei-5692-11-agosto-1971-357752-publicacaooriginal-1pl.html>.

BRASIL. Constituição Federal Brasileira de 1988. < http://www.planalto.gov.br/ccivil_03/constituicao/constituicao.htm>.

BRASIL. Lei n ${ }^{\circ}$ 9.394, de 20 de dezembro de 1996. <http://www.planalto.gov.br/ccivil_03/leis/19394.htm>.

BRASIL. Resolução CNE/CEB no 2/2001. Diretrizes Nacionais para a Educação Especial na Educação Básica. Brasília: Diário Oficial, 2001. http://portal.mec.gov.br/cne/arquivos/pdf/CEB0201.pdf>.

BRASIL. LEI No 10.436, De 24 de abril de 2002. http://www.planalto.gov.br/ccivil_03/leis/2002/110436.htm

BRASIL. Plano Nacional da Educação-PNE-2014. http://www.planalto.gov.br/ccivil_03/_ato2011-2014/2014/lei/113005.htm>.

BRASIL. Lei no 13.146, de 6 de julho de 2015. < http://www.planalto.gov.br/ccivil_03/_ato2015-2018/2015/lei/113146.htm>

BRASIL. Censo da Educação Básica | 2019- Notas Estatísticas Censo Escolar 2019. Publicado em 2020. http://portal.inep.gov.br/censo-escolar>

Cantini, J. H.; Ribeiro, L. O. A inclusão do surdo na sociedade sob a ótica dos Direitos Humanos. Missões: Revista de Ciências Humanas e Sociais, v. 5, n. 2, 2019 .

Carvalho, Rosita Edler. Educação Inclusiva: com os pingos nos is. 3. ed. Porto Alegre:Mediação, 2005.

Carvalho, J. M. et al. A integração de pessoas com deficiência. Revista Educação e Saúde. São João del Rei, v. 1, n.1, p. 98-102, set./mar. 2018.

Castro, H. V. Educação especial e inclusão de pessoas com deficiência na escola: um olhar histórico-social. 1986. $<$ https://eventos.fe.ufg.br/up/248/o/1.4._27_.pdf>. 
Coelho, C. P.; Soares, R. G.; Roehrs, R. Visões Sobre Inclusão Escolar No Contexto De Educação Especial: PCN X BNCC. Revista Educação e Políticas em Debate, v. 8, n. 2, p. 158-174, 2019.

Corrêa, M. A. M. Educação especial. Rio de Janeiro: Fundação CECIERJ, 2010.

Costa, M. T. A. Formação docente para a Diversidade. Curitiba: IESDE Brasil, 2018.

Graaf, G., Van Hove, G. Learning to read in regular and special schools: A follow-up study of students with Down syndrome. Life Span and Disability, 18(1), $7-39,2015$

Ferreira, M. C. C.; Ferreira, J.R. Sobre inclusão, políticas públicas e práticas pedagógicas. In GÓES, M.C.R.; LAPLANE, A.L.F. (Eds), Políticas e Práticas de educação inclusiva, $2^{\mathrm{a}}$ ed., p.21-48, Campinas, São Paulo, Brasil: Editores associados, 2007.

Fletcher, J. Spillover effects of inclusion of classmates with emotional problems on test scores in early elementary school. Journal of Policy Analysis and Management, 29(1), 69-83, 2010.

Garcia, E. Pesquisa bibliográfica versus revisão bibliográfica-uma discussão necessária. Línguas \& Letras, v. 17, n. $35,2013$.

Garcia, R. M.; Pereira, E. G. B. Educação especial, inclusão social e a meta 4 do PNE: um recorte no município do Rio de Janeiro. Revista Educação Especial em Debate, v. 3, n. 6, p. 116-136, jul/dez. 2018.

Gerhardt, T. E.; Silveira, D. T. Métodos de pesquisa.1ªed. Porto Alegre: Editora da UFRGS, 2009.

Gil, A. C. Métodos e técnicas de pesquisa social. 6. ed. São Paulo: Atlas, 2008.

Gottfried, M. A. Classmates With Disabilities and Students' Noncognitive Outcomes. Educational Evaluation and Policy Analysis, 36(1), $20-43,2014$.

Gomes, M. F.; Ferreira, L. J. Políticas Públicas e os objetivos do Desenvolvimento Sustentável. Revista Direito e Desenvolvimento, v. 9, n. 2 , ago/dez, 2018. https://periodicos.unipe.br/index.php/direitoedesenvolvimento/article/view/667.

Hehir, T.; Katzman, L. I. Effective inclusive schools designing successful schoolwide programs. San Francisco: Jossey-Bass, California, 2012. Disponível em: http://site.ebrary.com/id/10650970. Acesso em 02/09/21.

Jacomeli, M. R. M.; Barão, G. O. D.; Gonçalves, L. S. A política de educação integral no Brasil e suas relações com as diretrizes da conferência de Jomtien. Revista Exitus, v. 8, n. 3, p. 32-57, 2018.

Kassar, M. C. M. Percursos da Constituição de uma política Brasileira de educação especial inclusiva. Revista Brasileira Educação Especial, v.17, p. 41-58, mai-ago, Ed. Especial, Marília, São Paulo, 2011. https://www.scielo.br/j/rbee/a/QnsLXV5R9QBcHpTc4qMQ9Tr/?lang=pt\&format=pdf $>$.

Kauark, F. S.; Manhães, F. C.; Medeiros, C. H. Metodologia da pesquisa: guia prático. Itabuna: Via Litterarum, 2010.

Lima, P. A. Educação inclusiva e igualdade social. Brasil: Avercamp, São Paulo, 2006.

Lima, F. J.; SILVA, F. T. S. Barreiras atitudinais: obstáculos à pessoa com deficiência na escola. 2009.

Mantoan, M. T. E. Integração x Inclusão. Revista Pedagógica Pálio, v. 2, n. 5, p.48-51, São Paulo, 1998.

Mantoan, M. T. E. Teachers' education for inclusive teaching: refinement of institutional actions. In: Revue Francophone de la Déficience Intellectuelle. Colloque Recherche Défi. número spéciale, p. 52-54. Montréal/Québec, 1999.

Mantoan, M. T. E. Compreendendo a Deficiência Mental. São Paulo: Ed. Scipione, 1999.

Marques, J. D. Um olhar sobre o currículo inclusivo para além dos aspectos burocráticos. Educação Pública, v. 20, n $^{\circ} 21,2020$.

Mazzotta, M. J. S.; D’antino, M. E. F. Inclusão Social de Pessoas com Deficiências e Necessidades Especiais: cultura, educação e lazer. Revista Saúde e Sociedade, v. 20, n. 2, p.377-389, 2011. https://www.scielo.br/j/sausoc/a/mKFs9J9rSbZZ5hr65TFSs5H/?format=pdf\&lang=pt>.

Mendes, E. G. A radicalização do debate sobre inclusão escolar no Brasil. Revista Brasileira de Educação, Rio de Janeiro, v. 11, n. 33, p. 387-405, 2006. <http://www.scielo.br/scielo =S1413-. 24782006000300002\&lng=pt\&nrm=iso>.

Mercado, E. L.; Fumes, N. L. F. Base Nacional Comum Curricular e a educação especial no contexto da inclusão escolar. Encontro Internacional de Formação de Professores e Fórum Permanente de Inovação Educacional, v. 10, n. 1, 2017.

Mesquita, A. M. A. Currículo e educação inclusiva: as políticas curriculares nacionais. Espaço do Currículo, v. 3, n. 1, p. 305-315, 2010.

Moreira, W. S. et al. O Mediador Escolar no Segundo Segmento do Ensino Fundamental: Interlocuções entre Espaços, Desafios e Possibilidades da Inclusão Escolar. Educação em Revista, v. 19, n. 1, p. 137-154, 2018.

Mourão, A. B.; Netto, J. F. M. Modelo Inclusivo de Desenvolvimento de Objetivos de Aprendizagem Acessíveis para Apoiar a Educação Inclusiva. Tese de Doutorado apresentada nos Anais dos Workshops do Congresso Brasileiro de Informática na Educação (WCBIE), 2020. https://sol.sbc.org.br/index.php/wcbie/article/view/13024>.

Myklebust, J. O. Diverging paths in upper secondary education: competence attainment among students with special educational needs. International Journal of Inclusive Education, 11(2), 215-231, 2007. http://doi.org/10.1080/13603110500375432>. 
ONU. Plataforma Agenda 2030: acelerando as transformações para a agenda 2030 no brasil. < http://www.agenda2030.com.br/>

Parâmetros curriculares nacionais: Adaptações Curriculares/Secretaria de Educação Fundamental. Secretaria de Educação Especial. - Brasília: MEC/SEF/SEESP, 1998.

Parecer CNE/CEB nº 13/2009, MEC. 2009.

Paula, G. F. M.; SILVA, S. S. C. Educação inclusiva e as adaptações curriculares e metodológicas: um caminho a ser percorrido. Cadernos PDE, p. 1-21, 2016.

Peetsma T.T.D. et al. Inclusion in Education: Comparing pupils’ development in special and regular education. Educational Review, 53(2), 125-135, 2001. http://doi.org/10.1080/00131910125044>.

Peltier, G. The effect of inclusion on non-disabled children: A review of the research. Contemporary Education, 68(4), $234,1997$.

Prestes, I. C. P. Fundamentos teóricos e metodológicos da inclusão. Curitiba, PR: IESDE, 2015.

RESOLUÇÃO CNE/CEB Nº 2. Art. 5º, Inciso III, MEC. 2001.

RESOLUÇÃO CNE/CEB Nº 04/2009, MEC 2009. <http://portal.mec.gov.br/dmdocuments/rceb004_09.pdf>.

Ribeiro, E. et al. Inclusão escolar e barreiras atitudinais: um diálogo sob a perspectiva da sociologia de Pierre Bourdieu. Olhares: Revista do Departamento de Educação da UNIFESP. v.5, n. 2, p. 210-226, 2017.

Rubira, D. M.; Santos, F. S.; Martins, E. B. Um olhar para o processo de construção da cidadania diante da inclusão. In: X congresso Nacional de EducaçãoEDUCERE, Paraná, 2011. Disponível em:< https://educere.bruc.com.br/CD2011/pdf/5181_2865.pdf> Acesso em: 05 mar. 2021.

Ruijs, N. M.; Peetsma T. T. D. Effects of inclusion on students with and without special educational

needs reviewed. Educational Research Review, 4(2), 67-79, 2009. http://doi.org/10.1016/j.edurev.2009.02.002.

Sacristán, J. G. O Currículo: uma reflexão sobre a prática. $3^{\text {a }}$ ed. Porto Alegre: ARTMED, 2000.

Santos, J. M. O.; Lima, P. G. A Formação de professores e a educação inclusiva. Docent Discunt, v. 1, n. 1, p. 63-70, 2020.

Sharma, U.; Forlin, C.; Loreman, T. Impact of training on pre-service teachers' attitudes and concerns about inclusive education and sentiments about persons with disabilities. Disability \& Society, 23(7), 773-785, 2008. http://doi.org/10.1080/09687590802469271.

Silva, A. P. M.; Arruda, A. L. M. M. O Papel do Professor Diante da Inclusão Escolar. Revista Eletrônica Saberes da Educação, V. 5 , n. 1, p. 1-29, 2014.

Staub, D.; Peck, C. A. What Are the Outcomes for Nondisabled Students? Educational Leadership, 52(4), 36-40, 1995.

Unesco Institute for Statistics, \& UNICEF. Fixing the Broken Promise of Education for All: Findings from the Global Initiative on Out-of-School Children. Montreal: UNESCO Institute for Statistics, 2015. http://www.unicef.org/education/files/allinschool.org_wp-content_uploads_2015_01_Fixing-theBrokenPromise-of-Education-For-All-full-report.pdf.

Vargas, T. B. T.; Rodrigues, M. G. A. Mediação escolar: sobre habitar o entre. Revista Brasileira de Educação, v. $23,2018$.

Vygotski, L.S. Problemas del desarrollo de la psique. In: VYGOTSKI, L.S. (Org.). Obras escogidas (Tomo III). 2. ed. Moscú: Editoral Pedagógica, 1983.

Zanato, C. B.; Gimenez, R. Educação Inclusiva: um olhar sobre as adaptações curriculares. Revista@ mbienteeducação, v. 10, n. 2, p. 289-303, 2017. 